\title{
Hot air drying combined vacuum-filling nitrogen drying of apple slices: Drying characteristics and nutrients
}

\author{
Huang, X.L. ${ }^{a *}$; Li, T. ${ }^{\text {a }}$ Li, S.N. ${ }^{\text {a }}$ Wu, Z.H. ${ }^{\text {b Xue, J. }}{ }^{\text {a }}$ \\ ${ }^{a}$ College of Food Engineering and Nutritional Science, Shaanxi Normal University, Xi'an, 710119, \\ China \\ ${ }^{\mathrm{b}}$ College of Mechanical Engineering, Tianjin University of Science and Technology, Tianjin, 300222, \\ China
}

*E-mail of the corresponding author: cauxlhuang@hotmail.com

\begin{abstract}
In this paper, hot air drying (HAD) was applied when moisture content of apple slices range from $50 \%$ to $86 \%$, and then vacuum-filling nitrogen drying (VFND) was used till moisture content reaching 7\%. Results showed that, the drying rate of apple slice during VFND period increased with temperature increment and decreased with increment of slice thickness; compared to freezing dried samples, samples dried in this research were owned lower $V c$ and higher flavonoid; when $H A D\left(70^{\circ} \mathrm{C}, 3.0 \mathrm{~m} / \mathrm{s}\right)+V F N D$ (relative pressure $0.08 \mathrm{MPa}, 50^{\circ} \mathrm{C}$ ) and thickness of $6.0 \mathrm{~mm}$, nutrients reached better levels: retentions of $\mathrm{Vc}$, total phenolics and flavonoid were $1.63 \mathrm{mg} / 100 \mathrm{~g}$, $4.07 \mathrm{mg} / 100 \mathrm{~g}$ and $2.10 \mathrm{mg} / 100 \mathrm{~g}$, respectively.
\end{abstract}

Keywords: apple slices, hot air drying, vacuum-filling nitrogen drying, drying rate, nutrients 


\section{Introduction}

Apple is a main fruit in many countries. As the results from Wang and others, till 2013, the annual production of fresh apple fruit in China is about 39.7 million $t$, accounting for $49 \%$ of the global production ${ }^{[1]}$. Fresh apple fruits are usually graded for higher economic benefit. Fresh apples with the better quality would just be fresh consumed while the apples with the poor quality are generally used to produce juice, jam, and dried products for examples apple chips or nature apple powder and so on. Drying process of apple is a better way to prolong storage. And the main drying techniques used to dehydrate apple slices include FD, HAD, VD, HAD combined VD, and so on. HAD apple slices is the conventional technology studied widely in the past two decades ${ }^{[2-4]}$, however, browning and oxidation even hardening happened during $\mathrm{HAD}^{[5-7]}$, which induced undesirable quality. Freeze drying can produce perfect quality dried fruits and vegetables ${ }^{[8,9]}$, but it also high energy consumption. So, various combine drying methods applied to dry fruit and vegetable appear in recent years. Hazervazifeh et al. studied combined microwave-hot air and other drying methods dehydration of apple slices and found that, microwave power $2000 \mathrm{~W}$ at $70^{\circ} \mathrm{C}$ with the air velocity of $2.0 \mathrm{~m} / \mathrm{s}$ can induce the minimum drying time ${ }^{[10]}$. However, fruit and vegetable dried by microwave combined hot air does not always maintain the better quality, for example low rehydration ${ }^{[11]}$. Huang and others investigated effects of combined drying methods on composition, aroma, eating quality of apple slices ${ }^{[12]}$; in their studies, freezedrying, freeze-drying + microwave vacuum drying and microwave vacuum drying + freezedrying were used to dry apple slices; and the results showed that, microwave had significant effects on aroma, total phenols and pectin, and longer drying time high temperature at desorption drying stage and short time higher temperature at microwave vacuum drying period during freeze-drying + microwave vacuum drying induced lower retention of both aroma and reducing sugar. It was proved that vacuum drying can afford a low oxygen environment and the retention of various nutrients in vegetables and fruits could be better. Nitrogen is an inert gas and if it was filled with vacuum drying circumstance, it may be induce dried products with better quality.

The aim of this work is to study the drying characteristics of HAD + VFND dried apple slices and the quality of apples slice including retention of vitamin $\mathrm{C}$, total phenolics and flavonoid. For this purpose, experiments of apple slices dried after HAD and then dried in VFND under different conditions were conducted and nutrients were also determined.

\section{Materials and methods}

\subsection{Samples preparation}

Fresh apples malus pumila mill were obtained from local market and stored at $3-4^{\circ} \mathrm{C}$ in a refrigerator and were used within 14 days. The initial moisture contents of fresh apples were within 85 to $87 \%$ (wet basis), which were determined by hot air oven method at $103-105^{\circ} \mathrm{C}$ until the constant mass. Samples were sliced to the thicknesses of $2.0-8.0 \mathrm{~mm}$ after peeling and then immersed into $0.2 \%$ ascorbic acid solution for 2 minites to restrain browning. 


\subsection{Hot air drying}

Apple slices were dried with hot air at $70^{\circ} \mathrm{C}$ with the velocity of $3.0 \mathrm{~m} / \mathrm{s}$ after immersed into $0.2 \%$ ascorbic acid solution for 2 minutes and the moisture contents were declined from about $86 \%$ to $50 \%$ w.b. During hot air drying, the weights of samples were obtained by electronic balance with an accuracy of $0.001 \mathrm{~g}$ every 10 minutes.

\subsection{Vacuum-filling nitrogen drying}

The half dried apple slice samples were dried in vacuum-filling nitrogen drying oven until the moisture contents were about $7 \%$ w.b. In vacuum-filling nitrogen drying method, materials were put into vacuum oven, and then vacuuming $(10 \mathrm{kPa}) \rightarrow$ filling with nitrogen (near $0.1 \mathrm{MPa}) \rightarrow$ vacuuming $(10 \mathrm{kPa}) \rightarrow$ filling with nitrogen (near $0.1 \mathrm{MPa}$ ) $\rightarrow$ vacuuming $(10 \mathrm{kPa})$. Temperatures were range from 50 to $80^{\circ} \mathrm{C}$ during VFND. While during vacuumfilling nitrogen drying, the weights of samples were obtained every 20 minutes.

\subsection{Nutrients assay}

Dried apple slices were crushed by a pulverizer, and nutrients in nature apple powder were determined.

In this research, vitamin $\mathrm{C}$ was determined by Philin's reagent colorimetry according to the methods of Benassi \& Antunes ${ }^{[13]}$ and Marfil, Santos \&Telis ${ }^{[14]}$ with some modifications. Apples powder of $0.500 \mathrm{~g}$ was homogenized with the extraction solution ( $2 \mathrm{~g}$ oxalic acid $/ 100 \mathrm{~g}$ solution) and diluted to $50 \mathrm{ml}$ with the extraction solution in a volumetric flask, and then vacuum filtered after 30 minutes' standing. Filtrate of $10 \mathrm{ml}$ was taken for titration with 2,6dichlorophenolindophenol solution (50mg 2,6-dichlorophenolindophenol/250ml pure water). When the pink color of filtrate did not disappear in 15s, the titration end point was determined. All analyses were performed in triplicate.

The flavonoid content of apple powder was analyzed according the method described by Jia etal ${ }^{[15]}$ with slight amendments. $1.000 \mathrm{~g}$ apple powder was homogenized with $50 \mathrm{ml}$ of ethamol (7:10) for 60 minutes and then vacuum filtrated. $1.0 \mathrm{ml}$ of the filtrate was placed in a $25 \mathrm{ml}$ volumetric flask, $10 \mathrm{ml}$ of ethamol (7:10) and $1 \mathrm{ml}$ of NaNO2(1:20) were added and shaken well, $10 \mathrm{ml}$ of 1 mole per litre $\mathrm{NaOH}$ was added after 6 minutes, and the total volume was made up to $25 \mathrm{ml}$ with ethamol (7:10). After 15 minutes' standing, this sample was placed in colorimetric tube and the absorbance was measured at $510 \mathrm{~nm}$.

Total phenolics content of natural apple powder were determined by the Folin-Ciocalteau method $^{[16]}$. Apple powder of 1.000 grams were added to the ethanol solution with the content of $75 \%$ and diluted to $50 \mathrm{ml}$. $5 \mathrm{ml}$ of sample was taken into volumetric flask, $50 \mathrm{ml}$ of pure water and $4 \mathrm{ml}$ of Folin-Ciocalteu reagent were also added. After 3-4minutes' standing, 8ml of $10 \%$ sodium carbonate was put into the volumetric flask. And the final volume was made up to $100 \mathrm{ml}$ with pure water. After 120 minutes of reaction at $25^{\circ} \mathrm{C}$, absorbance at $765 \mathrm{~nm}$ was measured and used to calculate the phenolic contents using a standard curve prepared with gallic acid. All measurements were conducted in triplicate. 


\section{Results and discussion}

\subsection{Hot air drying characteristic of apple slice}

In this paper, drying rate was expressed as follow:

$$
D R=\frac{M C_{t-\Delta t}-M C_{t}}{\Delta t}
$$

Where $M C_{t-\Delta t}$ and $M C_{t}$ represented moisture content at the time of $t-\Delta t$ and $t$, separately, dry basis, \%; $t$ was drying time, min; and $\Delta t$ was time interval, min.

During HAD apple slices, there existed significant falling rate period, and the constant rate period was obvious for apple slices with the thickness of $2.0 \mathrm{~mm}$, while it was not evident for the apple slices with the thicknesses of $4.0-8.0 \mathrm{~mm}$, such as figure 1 . Because, there exists longer path and greater resistance in the thicker slices for water molecules migrating. Moisture content of apple slices declined more slowly as the increase of the slice thickness.

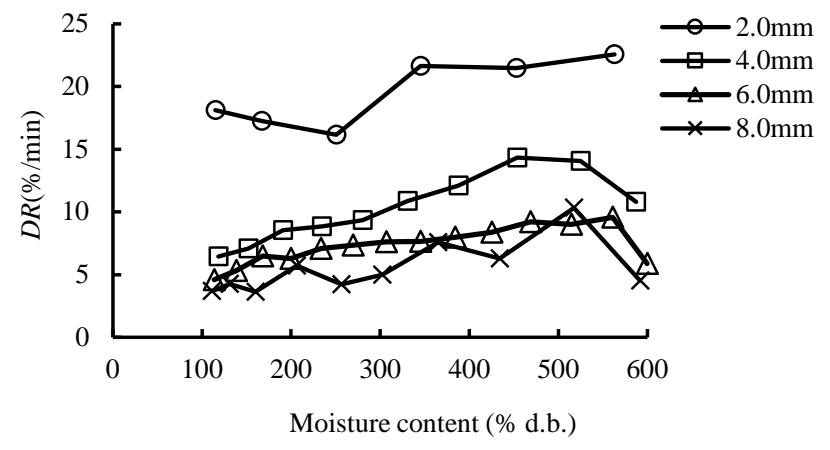

Fig. 1 Curves of dehydration rate of apple slices with different thicknesses during $\operatorname{HAD}\left(70^{\circ} \mathrm{C}\right.$,

$$
3.0 \mathrm{~m} / \mathrm{s})
$$

\subsection{Vacuum-filling nitrogen drying characteristics of apple slice}

After HAD, apple slices were dried with VFND until the moisture content lower than 7.0\%w.b. And there is only falling rate period for apple slices during VFND, showed in figures 2 and 3, owning to bound water in apple slices in this period.

During VFND, dehydration rate of apple slices declined as the decrease of temperatures and the increase of the slices thickness. As the analyzed above, there are the longer path and greater resistance for moisture to transfer to surface in the thicker apples slices. And when the thickness was $2.0 \mathrm{~mm}$, the greatest dehydration rate appeared which is approximate twice of that with the thicknesses of $6.0,8.0 \mathrm{~mm}$. The higher temperature, the greater drying rate is for apple slices dried in vacuum-filling nitrogen condition, and it was the same as the results from apple slices vacuum drying ${ }^{[17]}$. 


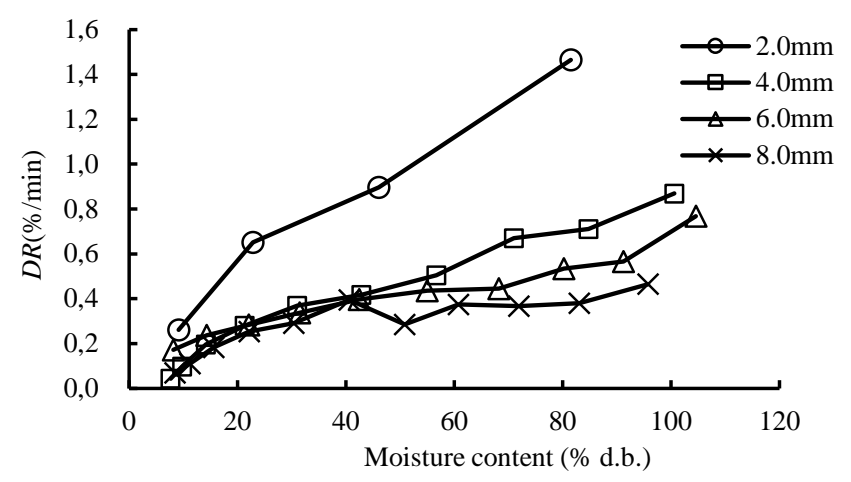

Fig. 2 Drying rate curves of apple slices during VFND with different thicknesses $\left(60^{\circ} \mathrm{C}\right)$

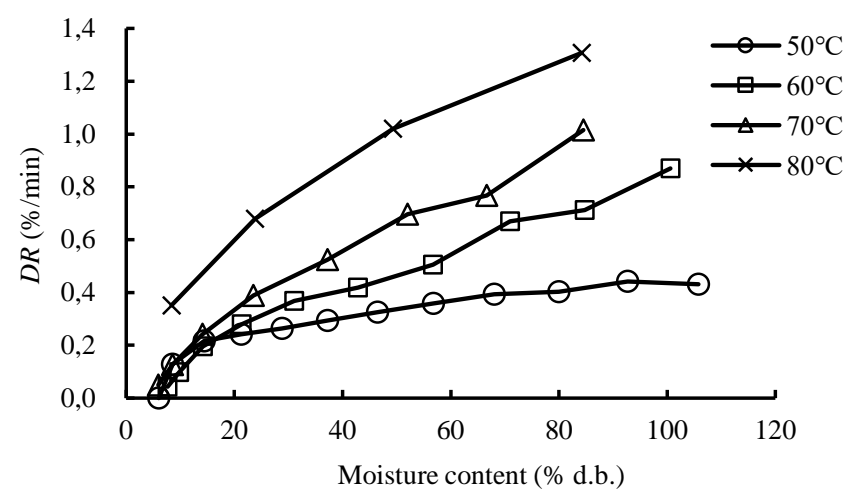

Fig. 3 Drying rate curves of apple slices during VFND at different temperatures (4.0mm)

\subsection{Nutrients of apple slice dried with combined drying methods}

Nature apple powder was made by the dried apple slices dried with different drying methods. And the nutrients of Vc, total phenolics, flavonoid in apple powder were expressed as $\mathrm{mg} / 100 \mathrm{~g}$ of initial fresh samples, showed in table 1 . From table 1 , it was found that, retentions of Vc in samples dried with HAD+VFND were lower than that of samples dried with FD, while the retentions of total phenolics of both samples dried with HAD+VFND and FD were at the same levels, and flavonoid retentions of samples dried with combined drying were almost higher to that of FD. Results reviewed that the combined method of HAD+VFND could be an available method for maintain flavonoid and total phenolics of apples; although vitamin $C$ in samples dried with HAD+VFND was lose seriously, just only about $30 \%$ to $52 \%$ of that in fresh apples. And when $\mathrm{HAD}$ at $70^{\circ} \mathrm{C}, 3.0 \mathrm{~m} / \mathrm{s}$ combined with VFND at temperature $50^{\circ} \mathrm{C}$, relative pressure $-0.08 \mathrm{MPa}$ and slice thickness of $6.0 \mathrm{~mm}$, nutrients in dried sample were better: the vitamin $C$ content of $1.63 \mathrm{mg} / 100 \mathrm{~g}$, total phenolics content of $4.07 \mathrm{mg} / 100 \mathrm{~g}$ and the flavonoid content of $2.12 \mathrm{mg} / 100 \mathrm{~g}$. In generally, it is available for HAD combined VFND to dehydrate apple slice. 
Table 1. Contents of nutrients in nature apple powder produced by various drying methods

\begin{tabular}{|c|c|c|c|c|}
\hline $\begin{array}{l}\text { Thickness } \\
\text { (mm) }\end{array}$ & $\begin{array}{c}\text { Temperature } \\
\left({ }^{\circ} \mathrm{C}\right)\end{array}$ & Vc (mg/100g) & $\begin{array}{l}\text { total phenolics } \\
\text { (mg/100g) }\end{array}$ & $\begin{array}{l}\text { flavonoid } \\
(\mathrm{mg} / 100 \mathrm{~g})\end{array}$ \\
\hline 2.0 & 50 & $1.38 \pm 0.03$ & $3.57 \pm 0.14$ & $2.10 \pm 0.06$ \\
\hline 2.0 & 60 & $1.50 \pm 0.03$ & $3.61 \pm 0.05$ & $1.71 \pm 0.03$ \\
\hline 2.0 & 70 & $1.29 \pm 0.03$ & $4.03 \pm 0.06$ & $1.55 \pm 0.04$ \\
\hline 2.0 & 80 & $1.04 \pm 0.05$ & $3.52 \pm 0.06$ & $1.39 \pm 0.03$ \\
\hline 4.0 & 50 & $1.81 \pm 0.03$ & $3.43 \pm 0.06$ & $1.20 \pm 0.02$ \\
\hline 4.0 & 60 & $1.32 \pm 0.09$ & $3.29 \pm 0.09$ & $1.21 \pm 0.04$ \\
\hline 4.0 & 70 & $1.26 \pm 0.06$ & $3.19 \pm 0.05$ & $1.03 \pm 0.04$ \\
\hline 4.0 & 80 & $1.66 \pm 0.06$ & $3.35 \pm 0.04$ & $1.08 \pm 0.02$ \\
\hline 6.0 & 50 & $1.63 \pm 0.09$ & $4.07 \pm 0.00$ & $2.12 \pm 0.07$ \\
\hline 6.0 & 60 & $1.49 \pm 0.02$ & $2.83 \pm 0.02$ & $1.55 \pm 0.01$ \\
\hline 6.0 & 70 & $1.58 \pm 0.02$ & $3.61 \pm 0.07$ & $1.77 \pm 0.09$ \\
\hline 6.0 & 80 & $1.58 \pm 0.02$ & $3.36 \pm 0.06$ & $1.83 \pm 0.08$ \\
\hline 8.0 & 50 & $1.74 \pm 0.05$ & $3.01 \pm 0.01$ & $1.46 \pm 0.04$ \\
\hline 8.0 & 60 & $1.55 \pm 0.08$ & $3.33 \pm 0.03$ & $1.58 \pm 0.04$ \\
\hline 8.0 & 70 & $1.38 \pm 0.03$ & $3.41 \pm 0.00$ & $1.67 \pm 0.09$ \\
\hline 8.0 & 80 & $1.23 \pm 0.09$ & $3.57 \pm 0.04$ & $1.80 \pm 0.05$ \\
\hline \multicolumn{2}{|c|}{$2.0 \mathrm{~mm}, \mathrm{FD}$} & $2.81 \pm 0.06$ & $3.72 \pm 0.02$ & $1.49 \pm 0.04$ \\
\hline \multicolumn{2}{|c|}{ fresh sample } & $3.51 \pm 0.21$ & $19.52 \pm 0.11$ & $6.39 \pm 0.22$ \\
\hline
\end{tabular}

Effects of temperatures during VFND period on vitamin $C$ retention of apple slices dried with HAD+VFND showed in table1. It was clearly found that, when the temperature was set 50 ${ }^{\circ} \mathrm{C}$ during VFND period, vitamin $\mathrm{C}$ content of samples dried with combined method was higher than others. Because, vitamin $\mathrm{C}$ is heat sensitive material and is decomposed seriously as the increase of the drying temperature ${ }^{[18]}$. However, the difference of vitamin $\mathrm{C}$ among all samples was not obvious when apples were sliced with different thicknesses.

Total phenolics in apple slice slightly declined with the increase of slice thickness. As thickness of apple slice became greater, drying time was longer that mean samples were exposed to high temperature condition for longer time, and it would induce lower retention of total phenolics.

Retention of flavonoid in samples was decreased firstly and then increased with the increase of slice thickness, showed in table1. When slice thickness was $2.0 \mathrm{~mm}$, flavonoid retention in 
apples slice was decreased with the increase of temperature, while the result was on the contrary when slice thickness was $8.0 \mathrm{~mm}$. The main reasons were that, it took short drying time to reach moisture content safe level when slice thickness was $2.0 \mathrm{~mm}$ at different drying temperatures during VFND period, and lower temperature can keep flavonoid at better level; however, the drying time became longer when slice thickness was $8.0 \mathrm{~mm}$ at all temperatures, especially at lower temperature, that means samples were exposed in the high temperature condition for long time.

\section{Conclusion}

In combined drying method of HAD+VFND, the drying rate of apples slice in VFND period was significantly affected by thickness and temperature. Retention of total phenolics and flavonoid in both samples dried with HAD+VFND and FD were at same levels although vitamin c was lower in samples dried with combined method. VFND might be an available drying technique for resisting oxidation reaction during drying process of fruits and vegetables.

\section{Acknowledgements}

The work was financially supported by the Fundamental Research Funds for the Central Universities of China (NO. GK201503072 and GK201601007).

\section{References}

[1] Wang, N.; Wolf, J.; Zhang, F.S. Towards sustainable intensification of apple production in China-Yield gaps and nutrient use efficiency in apple farming systems. Journal of Integrative Agriculture 2016,15(4),716-725.

[2] Zlatanović, I.; Komatina, M.; Antonijević, D. Low-temperature convective drying of apple cubes. Applied Thermal Engineering 2013,53(1),114-123.

[3] Velić, D.; Planinić, M.; Tomas, S.; Bilić, M. Ingfluence of airflow velocity on kinetics of convection apple drying. Journal of Food Engineering 2004,64(1),97-102.

[4] Nieto, A.; Salvatori, D.; Castro, M.A.; Alzamora, S.M. Air drying behavior of apples as affected by blanching and glucose impregnation. Journal of Food Engineering 1998,36(1),63-79.

[5] Martynenko,A.; Janaszek, M.A. Texture changes during drying of apple slices. Drying Technology 2014,32(5),567-577.

[6] Gong, Z.; Zhang, M.; Sun, J. Physico-chemical properties of cabbage powder as affected by drying methods. Drying Technology 2007, 25(5),913-916.

[7] Rajkumar, G.; Shanmugam, S.; Galvâo, M. S.; Sandes, R.D.D.; Neta, M.T.S.L.; Narain, N.; Mujumdar, A.S. Comparative evaluation of physical properties and volatiles profile of cabbages subjected to hot air and freeze drying. LWT-Food Science and Technology 2017, 80(7),501-509.

[8] Reyes, A.; Mahn, A.; Huenulaf, P. Drying of apple slices in atmospheric and vacuum freeze dryer. Drying Technology 2011,29(9),1076-1089. 
[9] Marques, L.G.; Freire, J.T. Analysis of freeze-drying of tropical fruits. Drying Technology 2005,23(9),2169-2184.

[10] Hazervazifeh, A.; Nikbakht, A.M.; Moghaddam, P.A. Novel hybridized drying methods for processing of apple fruit: energy conservation approach. Energy 2016, 103(1),679687.

[11] Seremet (Ceclu), L.; Botez, E.; Nistor, O.V.; Andronoiu, D.G.; Mocanu, G.D. Effect of different drying methods on moisture ratio and rehydration of pumpkin slices. Food Chemistry 2016, 195(1),104-109.

[12] Huang, L.L.; Zhang, M.; Wang, L.P.; Mujumdar, A.S.; Sun, D.F. Influence of combination drying methods on composition, texture, aroma and microstructure of apple slices. LWT-Food Science and Technology 2012, 47(1),183-188.

[13] Benassi, M.T.; Antunes, A.J. A comparison of meta-phosphoric and oxalic acids as extractant solutions for the determination of vitamin $\mathrm{C}$ in selected vegetables. Arquivos de Biologia e Tecnologia 1988, 31(4),507-513.

[14] Marfil, P.H.M.; Santos, E.M.; Telis, V.R.N. Ascorbic acid degradation kinetics in tomatoes at different drying condition. LWT-Food Science and Technology 2008,41(9),1642-1647.

[15] Jia, Z.S.; Tang, M.C.; Wu, J.M. The determination of flavonoid contents in mulberry and their scavenging effects on superoxide radicals. Food Chemistry 1999,64(4),555559.

[16] Yu, L.L.; Zhou, K.K.; Parry, J. Antioxidant properties of cold-pressed black caraway, carrot, cranberry, and hemp seed oils. Food Chemistry 2005, 91(4), 723-729.

[17] Vacuum drying of apples (cv. Goldon Delicious): drying characteristics, thermodynamic properties, and mass transfer parameters. Heat and Mass Transfer 2018, online first.

[18] Timoumi,S.; Mihoubi, D.; Zagrouba, F. Shrinkage, vitamin C degradation and aroma losses during infra-red drying of apple slices. LWT-Food Science and Technology 2007,40 (9),1648-1654. 